\title{
"Pioneira do progresso fluminense": o caso da industrialização de São Gonçalo (RJ) no século XX
}

"Pioneer of the fluminense progress": the case of the industrialization of São Gonçalo (RJ) in the century XX

"Pionera del progreso fluminense": el caso de la industrialización de São Gonçalo (RJ) en el siglo XX

"Pionniére du progrès à Rio de Janeiro": le cas de l'industrialisation de São Gonçalo (RJ) au 20ème siècle

José Luís Honorato Lessa

\section{(2) OpenEdition}

Journals

Edição electrónica

URL: http://journals.openedition.org/espacoeconomia/3296

DOI: $10.4000 /$ espacoeconomia.3296

ISSN: 2317-7837

Editora

Núcleo de Pesquisa Espaço \& Economia

Refêrencia eletrónica

José Luís Honorato Lessa, " "Pioneira do progresso fluminense": o caso da industrialização de São Gonçalo (RJ) no século XX », Espaço e Economia [Online], 12 | 2018, posto online no dia 14 julho 2018, consultado o 20 abril 2019. URL : http://journals.openedition.org/espacoeconomia/3296 ; DOI : 10.4000/espacoeconomia.3296

Este documento foi criado de forma automática no dia 20 Abril 2019.

(C) NUPEE 


\title{
"Pioneira do progresso fluminense": o caso da industrialização de São Gonçalo (RJ) no século XX
}

\author{
"Pioneer of the fluminense progress": the case of the industrialization of São \\ Gonçalo (RJ) in the century XX \\ "Pionera del progreso fluminense": el caso de la industrialización de São Gonçalo \\ (RJ) en el siglo XX \\ "Pionniére du progrès à Rio de Janeiro": le cas de l'industrialisation de São \\ Gonçalo (RJ) au 20ème siècle
}

José Luís Honorato Lessa

Tens usinas com muitas chaminés

Que logo dizem prontas quem tu és;

Oficina onde bate rijo o malho ${ }^{1}$

\section{Introdução}

O município de São Gonçalo ${ }^{2}(\mathrm{SG})$ é portador de um boom industrial no século XX. Tanto o hino quanto o brasão da cidade prestam referência a este passado. A partir da histórica concentração industrial foi alcunhada de Manchester Fluminense. Pensamos este evento gonçalense no recuo da última década do século $\mathrm{XIX}^{3}$. Nos embates para a conquista da autonomia político-administrativa em relação a antiga capital estadual - Niterói, as forças políticas locais visualizaram a consolidação de tal municipalidade pari passu ao progresso da região. Assim, vale destacar as isenções de impostos municipais para implantação das fábricas (AZEVEDO, 1939), somados a outros fatores: geografia de acesso rápido às capitais estadual e federal - respectivamente, Niterói e a cidade do Rio de Janeiro - onde rios e portos ligavam facilmente SG à Baía de Guanabara e seu intercâmbio com o porto do Rio; outra parte desta infraestrutura era complementada pelas ferrovias - Estrada de Ferro Maricá e Estrada de Ferro Niterói-Cantagalo. Estas, articuladas ao Porto das Neves, 
gabaritava SG como vértice de ligação à capital federal e ao interior norte-noroeste do Estado do Rio de Janeiro (ERJ), (PALMIER, 1940, p.76). Desse modo, temos a formação das primeiras manufaturas na região e no entorno. Beauclair e Honorato chamam este processo de pré-indústria (1977). O século XX veio com grande impulso: no recenseamento de 1920 consta a existência de 21 indústrias operando em SG.

\section{A São Gonçalo pós 1930: indústria e urbanização.}

2 Os efeitos do Brasil pós 1930 se fizeram sentir em SG. Um detalhe é que sua produção industrial encontrava-se em estágio crescente enquanto o ERJ já havia perdido a dianteira para São Paulo. Por outro lado o pós 1930 demarca a crise agrícola da região em sua tradicional produção de cítricos. Conforme dados extraídos do IBGE, em 1920 o percentual da população local economicamente ativa apresentava-se assim: $44,29 \%$ da força da mãode-obra na atividade agrária; as indústrias demandavam ocupação de $24,53 \%$ enquanto 31,18\% eram distribuídos entre o terceiro setor. Em 1920 o município possuía 48.019 habitantes, já em 1940 este número saltou para 85.528. Em face da atividade industrial e comercial verifica-se um crescimento constante da zona urbana acompanhado pela febre de loteamentos, como constatou Mendonça (1996).

O número de trabalhadores na atividade agrícola conforme o censo de 1940 sofre redução o que revela a estagnação do setor cujo desfecho da crise atribui-se as dificuldades de exportação de cítricos com a eclosão da segunda Guerra Mundial. Neste mesmo período, notabiliza grande crescimento dos setores secundário e terciário em SG e a consequente expansão urbana. Conclui-se que a população gonçalense aumentou em mais de um terço em 10 (dez) anos. Dados da Agência Local de Estatística apontam: a) o crescimento populacional na sede do município ( $1^{\circ}$ Distrito) entre 1940 e 1950 foi em média de $16 \%$ ao ano que saltou de 8.484 (1940) para 22.000 habitantes em (1950) e, b) nos outros dois distritos da zona urbana - Neves ( $4^{\circ}$ Distrito) e Sete Pontes ( $5^{\circ}$ Distrito) a concentração demográfica também foi significativa. No caso do $5^{\circ}$ Distrito, este passou de $24.017 \mathrm{em}$ 1940, para 27.450 mil habitantes em 1950. Por sua vez, o $4^{\circ}$ Distrito saltou de 34.181 para 52.000 mil habitantes durante o mesmo período, crescimento equivalente a $53 \%$ numa média anual em torno de $5 \%$.

4 De acordo ainda com os dados do IBGE, a população de SG na década de 1940 aumentou em 37,748 habitantes, incremento anual em torno de 3,7\%. Estes números podem até parecer enfadonhos, mas antes de tudo refletem a prosperidade do município considerado à época um dos mais importantes do ERJ sob o ponto de vista industrial. Em 1950 o quantitativo da população urbana supera a população rural, conclui-se que: com quase $80 \%$ da população gonçalense fora do quadro rural, o município concentrava expressivamente sua população na área urbana (IBGE, 1950, p.84). Esta alta demográfica é também consequência do declínio da própria agricultura fluminense que inexoravelmente demarcou para a chamada Região Metropolitana vertiginoso crescimento populacional. Somado a isso, municípios como Duque de Caxias, São João de Meriti e Nova Iguaçu receberam a partir de 1940 significativas levas de populações oriundas de outras unidades da federação, especialmente do norte e nordeste.

Por outro lado, segundo Geiger (1956), ao longo do século XX a expansão urbana da cidade do Rio de Janeiro levou a instalação de fábricas na orla oriental da baía da Guanabara, particularmente nas regiões de Niterói e SG. Com efeito, conforme o Censo Industrial do 
ERJ em 1940 havia 83 estabelecimentos industriais em atividade em SG. Para 1950 operavam 117 empresas no município cujo valor da produção industrial já superava o de Niterói de onde SG era egresso e lutava por cristalizar sua autonomia. Ainda conforme Geiger (1956), em SG, as indústrias de base, notadamente, cimento, química e metalurgia, - predominam - ao passo que em Niterói destacam-se pequenas empresas como sapatarias, padarias e oficinas.

6 Perseguindo as informações do IBGE, o Recenseamento Geral de 1960, apontava 252 estabelecimentos industriais. Outra fonte nos informa o seguinte:

“Um dos mais importantes municípios fluminenses no setor econômico. A industrialização gonçalense atingiu um dos mais elevados níveis e é responsável pela maior parte de sua arrecadação (...). Seu comércio é dos mais movimentados do Estado, mesmo sofrendo a natural concorrência de praças mais adiantadas, como Niterói e Rio de Janeiro (...), dia após dia cresce o comércio local, colocando em posição de amplo destaque. O surto do progresso, nestes últimos 5 anos é verdadeiramente assustador. A industrialização do pescado é a mais importante do país. As maiores fábricas de conservas estão localizadas ali" (PEÇANHA, 1962. p.5)

$7 \mathrm{Na}$ verdade, as indústrias em SG protagonizavam crescimento quantitativo desde as primeiras décadas do século XX. Segundo Geiger (1956), entre 1920 e 1940, foram instaladas na cidade importantes unidades no setor de metalurgia, cimento, cerâmicas e de conservas. Conforme já aludimos o quantitativo das indústrias nos dados censitários de 1940, 1950 e 1960 apresentam os seguintes números de estabelecimentos: 83, 177 e 252, respectivamente.

\section{A tradicional planta industrial gonçalense}

Algumas indústrias do antigo modelo industrial gonçalense demandavam complexidade produtiva. No ramo da construção destaque para a Companhia Nacional de Cimento Portland. Esta possuía complexo sistema produtivo com 3 unidades de usina termoelétrica, canal navegável de uso próprio, sistema de chatas, ferrovia, trens de carga e caminhões. Na produção metalúrgica sobressaía a Companhia Brasileira de Usinas Metalúrgicas (CBUM).

Para ilustrar o caso da CBUM, antes de ser conhecida como tal, passou por várias denominações em função das transferências de concessões. Situada no distrito de Neves e controlada pelo Loyde Brasileiro transferiu-se para o Grupo Hime em 1920. Este de capital nacional e dirigido pelos senhores Francis Hime, Júlio Monteiro, Luiz Pinto, Renato Wood e Almiro Pedreira (BRAGA, 2006, p.156). o que se tornou a Siderúrgica Hime S.A tem sua origem na segunda metade do século XIX através de atividades de mineração nos rios paulistas: Jacupiranguinha e Turvo. Em SG a Hime detinha o controle do Porto de Neves. Antes de receber o denominativo CBUM, chamou-se Fundição Acieira Martins que já no início da década de 1940 superava a marca de mil funcionários (Palmier, 1940: 122). Dois documentos da década de 70 apontam que em 1976 a empresa possuía 1.709 operários ocupados, em 1979, este número era de 1.664 trabalhadores. Inserida no modelo manchesteriano - a empresa mantinha escola primária, de corte-costura, além da vila operária. Tal companhia foi incorporada pelo Grupo Gerdau em 1985. Em 1987, com aproximadamente 900 funcionários, produziu quase 79 mil toneladas de aço, $4 \mathrm{mil}$ toneladas de trefilados e 3 mil toneladas de produtos farpados. 

de Fósforos; Companhia Fiat Lux e Companhia Indústria de Papéis Alcântara. No ramo da indústria de material para condução de energia e Vidros: Companhia Vidreira do Brasil COVIBRA, fundada em 1941, para esta indústria há uma confusão denominativa que não conseguimos esclarecer, também foi conhecida como Indústrias Reunidas do Brasil que a partir de 1978 passou a se chamar Eletro Vidro - de capital francês, produzia isoladores de vidros para transmissão de energia de média e alta tensão. A empresa atendia ao mercado nacional e internacional, em 1987 possuía 380 funcionários. No ramo de vidros havia ainda a Indústrias Reunidas Mauá S.A.

Das indústrias de pescado (conservas): Companhia Brasileira de Produtos de Pesca S. A; Conserva Orleans; Conserva Rubi; Conserva União; Fábrica de Conserva Ondina; Fábrica de Conserva Piracema; Indústrias de Conservas Coqueiro (ainda em funcionamento) e Indústrias Reunidas de Pesca Netuno S.A. No campo das indústrias do setor químico: Companhia Eletro Química Fluminense (com quase 200 operários em 1959); Fábrica de Silicato de Sódio e a Companhia S.A Composições Internacional, hoje denominada de Tintas Internacional, encontra-se em funcionamento controlada pelo grupo Akzo Nobel.

Pois bem. Quase a totalidade desta planta industrial encerrou suas atividades. Basicamente sediada na região do $4^{\circ}$ Distrito de Neves, o colapso da região foi associado como se fosse de todo o município meio que empurrando definitivamente a atividade produtiva gonçalense para o buraco antes mesmo da década de 1960. Na verdade, muitos destes estabelecimentos mantiveram suas atividades pelo menos até o início da década de 1980.

O jornal 0 Fluminense informa que em 1980 as 11 (onze) empresas que mais contribuíam (pela ordem) para os cofres públicos municipais eram: (i) Siderúrgica Hime S/A; (ii) Conservas Coqueiro S/A; (iii) Companhia Nacional de Cimento Portland; (iv) Fiat Lux S/A; (v) Laboratório B. Braun S/A; (vi) Indústria de Conservas Rubi S/A; (vii) Refrigerantes Niterói S/A (fabricante de uma famosa marca regional - o refrigerante Mineirinho); (viii) Indústria de Tintas Internacional S/A; (ix) Guanabara Química Industrial - Getec S/A; (x) Amplastic S/A e (xi) Eletro Vidro S/A.

14 Ressaltamos que a $10^{\mathrm{a}}$ contribuinte denominada de Amplastic S/A não aparece no Cadastro Industrial do ERJ de 1979 elaborado pela Federação das Indústrias do Estado do Rio de Janeiro (FIRJAN). Por analogia nossa, a indústria em questão parece ser do gênero material plástico; no documento da FIRJAN consta um estabelecimento com 131 empregados cuja denominação é - Almoplast Indústria e Comércio Ltda. Todavia, para ilustrar, neste setor havia duas outras empresas com significativo número de empregados: Custódio Rangel Pires \& Cia. Ltda e a Fraspol Indústria e Comércio Ltda, respectivamente com 160 e 209 empregados.

\section{A nova planta industrial gonçalense}

Entre os novos setores industriais destaques para as atividades têxteis, químicofarmacêuticas e equipamentos médicos. Uma das produções que deu forma à atividade econômica do município após 1960 foi o setor de confecção de roupas, especialmente a moda jeans, presente em todos os distritos, como se observa na figura abaixo: 


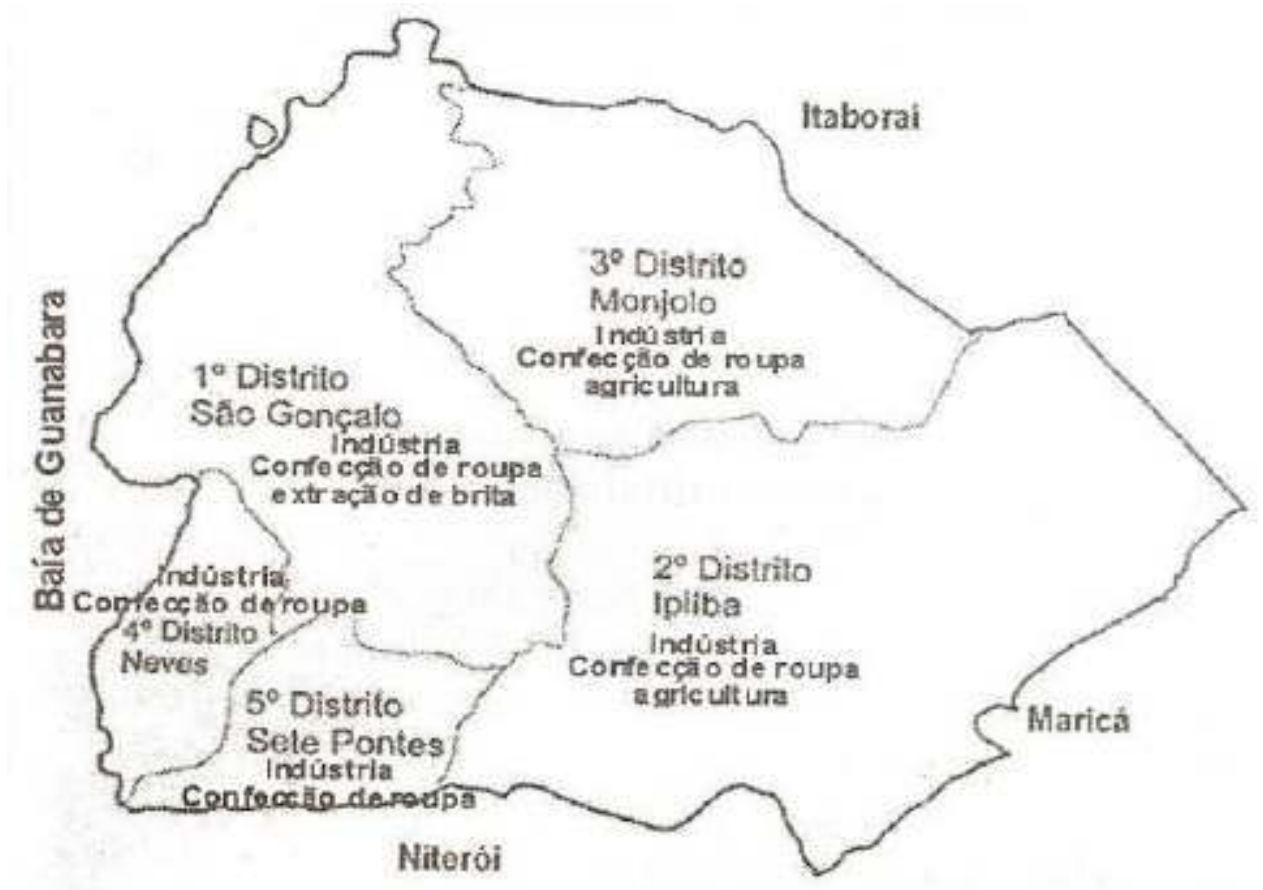

Fonte: (BRAGA, 2006. p. 148)

$\mathrm{O}$ advento da moda jeans articula-se a conjunturas bem mais amplas. $\mathrm{O}$ jornal $O$ São Gonçalo em novembro de 1965 se reportava a uma lei, assinada pelo governo Castelo Branco, assessorado pelos ministros Gouveia Bulhões e Roberto Campos. O argumento defendido pelo noticioso local era de que o ato impulsionaria a indústria de fiação e tecelagem do antigo ERJ. A medida concedia estímulos especiais às indústrias têxteis, de couros, calçados e de artefatos na qual o objetivo fim consistia em incentivos que modernizassem os equipamentos bem como o padrão produtivo. 0 elemento principal concentrava na isenção de impostos de importação até 1968. Com tal perspectiva, acreditava-se em impactos imediatos nos meios empresariais de Niterói, SG, Petrópolis, Barra do Pirai, Valença, Macaé, Campos e Miracema, municípios em que se sustentava ou se iniciava o registro do ciclo industrial têxtil.

Embora não identificado na figura 1 , as indústrias químico-farmacêuticas e de equipamentos médicos consolidaram importante polo no bairro do Arsenal, localizado no segundo distrito e cortado pela RJ 106. As empresas em destaque são: Laboratórios B. Braum (capital alemão); Ranbaxi (capital americano e indiano) e Hartmann Indústria e Comércio de Produtos Médico-hospitalares (capital nacional).

Para ilustrar o que classificamos de nova planta industrial gonçalense acompanhemos com mais proximidade a seguinte contribuição:

“(...). São Gonçalo tem ainda o segundo parque industrial do Estado no que se refere à diversificação - é ultrapassado somente pela capital -, porém ainda muito pouco conhecido pela sociedade fluminense e carioca. 0 município não sofreu o processo de emancipação como Nova Iguaçu, que perdeu os distritos industriais mais importantes, o que lhe confere unidade territorial e um importante peso no arranjo urbano-industrial metropolitano. (...). A análise da distribuição do número de estabelecimentos permite identificar uma heterogeneidade própria de um antigo centro industrial. O município já passou por momentos de abertura, fechamento e 
reabertura de empresas, assim como a transformação do seu perfil, com o fechamento de grandes unidades industriais e a abertura de pequenas empresas na mesma atividade. (...)" (FREIRE e FREIRE, 2006. pp. 346 e 352). processo de reestruturação, diversificação e (re) espacialização. Identificamos atividades industriais por todos os distritos, conforme exemplificado na figura 1. Oliveira em estudo de doutoramento que discute a questão da reestruturação produtiva fluminense, mudanças na dinâmica de produção e na gestão do território, ao operar com os censos industriais do IBGE para os anos de 1975, 1980 e 1985 - aponta para SG, tal como para as cidades do Rio de Janeiro e Nova Iguaçu, a ocorrência de uma produção diversificada (OLIVEIRA, 2003, pp. 63 e 65.).

Mas é fundamental ressaltar o fato de que não estamos diante de uma situação completamente nova. A diversidade do parque industrial gonçalense sempre foi digna de nota pela historiografia local. São comuns referências às indústrias de vidro, cimento, ferro, produtos químicos, pescado, derivados de cerâmicas, fósforos e muitas outras. No pós-1960, o que se verifica é o destaque da atividade industrial em novos setores: caso da moda jeans; da indústria alimentícia e do ramo de laboratório farmacêutico. Excetuandose o setor de conservas de pescado, que permaneceu em seu espaço característico, ou seja, a orla guanabarina do município, as novas atividades produtivas podem ser relacionadas ao fenômeno da reestruturação e da (re) espacialização da atividade produtiva gonçalense cujo perfil industrial manteve-se importante no conjunto do município e do Estado. É o que veremos a seguir.

\section{A indústria em números}

21 É necessário chamar a atenção para a participação industrial do município de SG inclusive no período considerado como de crise. Além da imprensa regional, percebemos em diferentes fontes a figuração da cidade entre as mais importantes do Estado, mesmo durante a segunda metade do século XX. No histórico de concentração industrial na região do Grande Rión , é fundamental destacar o papel desempenhado por municípios como SG, Niterói, Nova Iguaçu e Duque de Caxias desde a década de 1930. No final daquele decênio estes municípios representavam mais de $70 \%$ do valor da produção industrial da área (CERJ, 1993, p. 26). Tabelamento do Censo Industrial do ERJ do ano de 1940 - IBGE destaca os cinco primeiros municípios fluminenses no que se refere ao valor industrial: SG figura em $5^{\circ}$ lugar em quantitativo de estabelecimento industrial, atrás de Campos, Niterói, Petrópolis e Nova Iguaçu; o $2^{\circ} \mathrm{em}$ capital aplicado - perdia apenas para a cidade de Campos e perseguido respectivamente por Petrópolis, Niterói e Nova Iguaçu; o 4ํํㄱ lugar em pessoal ocupado e o $2^{\circ}$ em valor de produção. A liderança ficava com o município de Petrópolis - sequenciado por Niterói, Campos e Nova Iguaçu.

O fato de SG ter ocupado a $2^{\mathrm{a}}$ colocação em capital aplicado e em valor de produção, apesar de ser o $5^{\circ}$ em números de estabelecimento, pode resumir a alta complexidade daquela atividade. Este arrazoamento também encontra eco no tabelamento muito específico entre 3 dos mais centrais municípios metropolitanos: Niterói, Nova Iguaçu e SG, divulgado em 1950 pelo IBGE, onde a cidade assume a dianteira quanto à força motriz empregada.

23 Os dados do IGBE para 1960 consideram os cinco primeiros municípios fluminenses em termos industriais: Campos, Duque de Caxias, Niterói, SG e Nova Iguaçu. Balizados os 
dados de 1940 a 1960, o município salta da $5^{\mathrm{a}}$ para a $4^{\mathrm{a}}$ colocação quanto ao número de estabelecimentos e, embora o município tenha perdido posições: uma (1) em termos de pessoal ocupado e duas (2) em valores de produção, a atividade industrial local era a $2^{\mathrm{a}} \mathrm{em}$ utilização da força motriz - atrás de Campos. Na sequência se apresentavam Nova Iguaçu, Duque de Caxias e Niterói.

Ora, estes dados também têm permitido colocar reticências à ideia de crise aguda do setor e a consequente desindustrialização quase que total do município. Em edição número 2.373 de 1960, O São Gonçalo estampava a matéria "São Gonçalo: aspecto industrial" - na oportunidade, reproduzia dados de 1959, atribuídos ao Conselho Técnico de Economia e Finanças. Excetuando as capitais, o conteúdo jornalístico apontava os onze (11) municípios do ERJ que figuravam entre os cem (100) mais do país em arrecadação de impostos. SG era o $6^{\circ}$ colocado entre os municípios fluminenses e o $27^{\circ}$ do país.

Desse modo, não compartilhamos do argumento generalizante acerca da crise no setor industrial gonçalense. Temos após 1960 um quadro produtivo local não menos importante no cenário fluminense. Se olharmos isoladamente para dentro do município, de fato, veremos uma paisagem de fechamento de alguns setores, não obstante, se assumirmos perspectiva do conjunto estadual, o retrato que está por revelar é outro: a crise na proporção que é propalada não se apresenta enquanto tal.

De acordo com a publicação do IBGE (1970), em 1965, SG era o $5^{\circ}$ município do Estado em valor de produção. Veremos na tabela a seguir que para este ano o valor das vendas industriais no âmbito estadual gabaritava SG na $5^{\text {a }}$ colocação. Cumpre observar o município enquanto espaço de atividade industrial intensa.

Tabela 1: Valor das Vendas Industriais em 1965 em NCR\$ 1. 000

\begin{tabular}{|l|c|}
\hline 1- Duque de Caxias & 418.207 \\
\hline 2- Volta Redonda & 302.068 \\
\hline 3- Niterói & 93.023 \\
\hline 4- Petrópolis & 88.660 \\
\hline 5- São Gonçalo & 84.946 \\
\hline 6- Nova Iguaçu & 70.818 \\
\hline 7- Barra Mansa & 68.458. \\
\hline 8- Campos & 66.877 \\
\hline
\end{tabular}

Fonte: (CIRJ E FIEG, 1969, p.41)

Os valores das vendas industriais igualmente contribuíram para o destaque gonçalense naquele período, em superação a outras 3 importantes cidades da conjuntura fluminense. A relevância industrial de SG pode ser sentida quando analisamos em outro conjunto de fonte as características do valor da produção industrial da Região Metropolitana do Rio de Janeiro (RMRJ) em 1960, 1970 e 1978. Observa-se que ao excetuar a capital, SG sustenta a $5^{a}$ posição no que tange ao Valor da Produção Industrial nos três períodos pesquisados. Mais uma vez estamos diante de um município com substancial importância do setor cuja participação no conjunto fluminense revela um problema se se pensar na ocorrência de crise mesmo antes da década de 1960. 


\section{O período posterior a 1970} união público-privada. Argumentava: tal era a condição de desenvolvimento que o município alcançou a posição de $3^{\circ}$ parque industrial Estado (sem precisar o período), atrás de Duque de Caxias e Volta Redonda. Seja como for, a participação gonçalense no quadro produtivo fluminense não tinha perdido seu peso. Neste momento vamos ver como se comportou o valor da transformação industrial (VTI) gonçalense nos anos 1975, 1980 e 1985 - entre "os principais núcleos industriais do Estado" (OLIVEIRA, 2003, p. 63).

Tabela 2: Quadro comparativo do VTI gonçalense no conjunto da RMRJ e do Estado entre de 1975 a 1985

\begin{tabular}{|l|l|l|l|}
\hline & 1975 & 1980 & 1985 \\
\hline RMRJ & $5^{\circ}$ & $6^{\circ}$ & $4^{\circ}$ \\
\hline ESTADO & $7^{\circ}$ & $7^{\circ}$ & $6^{\circ}$ \\
\hline
\end{tabular}

Fonte : Tabela elaborada pelo autor deste artigo conforme Oliveira (2003:63).

A partir desta comparação é possível nuançar outro quadro: certa "estabilidade" do setor. Naquele momento ainda que a indústria gonçalense correspondesse com $1.50 \%$ para o VTI estadual, por outro lado, cumpre observar que a manutenção destas posições ocorria em meio aos anos 1980. Tomado como um dos momentos mais nevrálgicos da desestruturação econômica do ERJ (Oliveira, 2003: 66/70).

Para o ano de 1970, o IBGE apontava 424 estabelecimentos industriais na cidade de SG. Outra fonte analisada por nós reúne os dez municípios fluminenses de maior participação no setor industrial no que tange a estabelecimentos e produção (Cr\$ milhões) em 1975, conclui-se que SG figurava como o $8^{\circ}$ do Estado e o $5^{\circ}$ da RMRJ. O Guia Socioeconômico dos Municípios do Estado do Rio de Janeiro nos oferece outros elementos. $O$ documento expõe a situação do Produto Interno Bruto (PIB) municipal no ano de 1980, caracterizada na figura 2: 
Figura 2: São Gonçalo 1980. PIB por setor de cada atividade municipal.

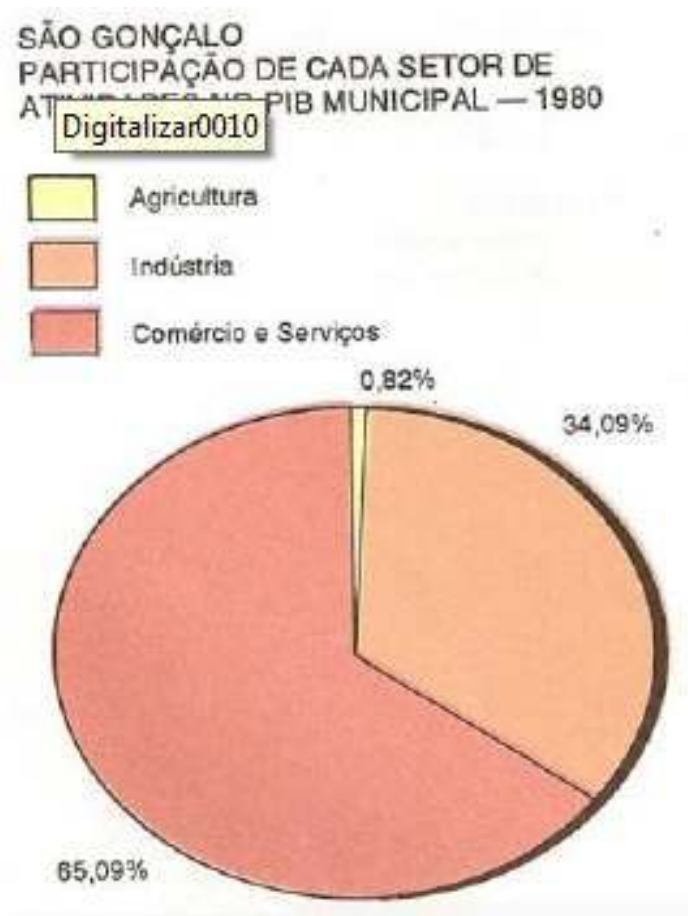

FONTE: ANUÁRIO ESTATístico dO RIO DE JANEIRO, CIDE, 1990/91.

Esta fonte toma SG como um dos mais importantes municípios do Estado: à época

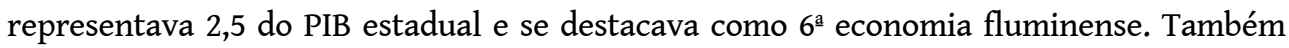
em 1980 a População Economicamente Ativa (PEA) municipal era assim constituída: 1\% para o setor primário; $32 \%$ para o setor secundário (deste percentual a indústria de transformação correspondia com cerca de $20 \%$ e $67 \%$ para o terceiro setor da atividade econômica. Na tabela 3, em tela o comparativo do PIB do Estado, da RMRJ e de SG no ano de 1980:

Tabela 3: Comparativo do PIB - Estado, RMRJ e São Gonçalo. 1980.

\begin{tabular}{|l|l|l|l|}
\hline SETORES & ESTADO & RMRJ & SÃO GONÇALO \\
\hline AGRICULTURA & $2 \%$ & 0,35 & $0,82 \%$ \\
\hline INDÚSTRIA & $38 \%$ & $30 \%$ & $34,09 \%$ \\
\hline COMÉRCIO E SERVIÇOS & $60 \%$ & $69.65 \%$ & $65,09 \%$ \\
\hline
\end{tabular}

Fonte : Organizado pelo autor deste artigo conforme GUIA SOCIOECONÔMICO DOS MUNICÍPIOS DO ESTADO DO RIO DE JANEIRO, 1993. pp. 27, 50 e 132

É necessário que se chame atenção para a polarização do PIB na RMRJ em 1980. Considerando a totalidade do Estado, a mancha metropolitana fluminense concentra $18 \%$ do PIB agrícola, 77\% do PIB industrial e $88 \%$ para comércio e serviços. Em relação ao PIB geral do Estado, a RMRJ polarizava 83\%. A profunda concentração industrial no entorno metropolitano fluminense também é refletida por Limonad. A autora aponta que em 1980, 58,92\% do VTI estadual estavam concentrados na região. (LIMONAD, 1996, p.15.). Todavia, 
esta questão não era absolutamente nova, ainda na conjuntura anterior à fusão, veja o seguinte perfil traçado:

O setor industrial é extremamente concentrado no espaço estadual. Em 1973 quase $80 \%$ do valor da produção do antigo Estado do Rio de Janeiro provinham dos municípios de Duque de Caxias, Volta Redonda, Campos, São Gonçalo, Niterói, Nova Iguaçu Petrópolis e Barra Mansa; quatro dentre eles pertencentes [ou: que mais tarde pertenceriam] à região metropolitana (LIMONAD. 1996, p.134).

Para retornar a tabela 3 quanto ao PIB industrial, na variação das escalas não se percebe grandes distanciamentos. Nas três configurações o PIB industrial sempre permaneceu na casa dos $30 \%$. Mesmo assim a SG é conhecida por sua natureza eminentemente varejista e dormitória. Ainda que sejam proposições relevantes vemos que condicionar isto à evidência de evasão das indústrias é que tem sido o grande problema. A equação não apresenta esta linearidade tão cristalina. Aqui oferecemos uma hipótese que carece de investigação. O aumento da taxa de desemprego na cidade foi impulsionado mais pelo fechamento de algumas unidades industriais e menos pelo crescimento desordenado da população? A questão se apresenta aberta: é preciso estudar a equação entre crescimento da população e o aumento do desemprego, a priori, a atividade industrial não cresceu de modo proporcional à população, onde a carência de postos de trabalho na região impulsionou a procura por empregos em outras praças, justificando a adjetivação de cidade dormitório.

A tese do esvaziamento industrial sob o argumento de que a principal atividade econômica do município concentra-se no comércio varejista nos parece pouco viável ou aguarda novos estudos. Aliás, mesmo no auge da indústria, a agricultura local foi a principal empregadora. Atualmente este papel é desempenhado pelo comércio e serviços. Ou seja, a mão-de-obra utilizada no setor secundário nunca superou os demais. Quanto ao crescimento da população não acompanhado pela oferta de postos de trabalho, encontramos evidências no que se segue:

São Gonçalo é uma cidade com predominância operária, porém não comporta a mão-de-obra local, que assim recorre às cidades de Niterói e Rio de Janeiro. Embora em expansão em todos os setores da economia, ainda não conseguiu o município reverter a evasão de divisas e mão-de-obra que favorecem as cidades citadas. (BRAGA, 2006. p. 162.)

\section{Perfis das movimentações de 1985 e de 1990: número de estabelecimentos e pessoal ocupado}

As análises seguintes baseiam-se em dados do Ministério do Trabalho contidos nos indicadores sociais Rais/ Caged. Inicialmente traçaremos perfil dos setores produtivos por funcionários. Ao interpretarmos informações denominadas "Número de estabelecimento por grandes setores e quantidade de funcionários - SG (RJ). 1985" - identificamos que em

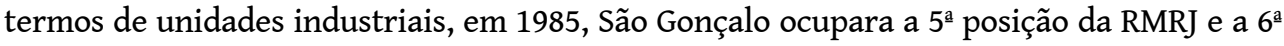
do Estado, no total de 73 municípios analisados. Já no setor de comércio sustentava a $4^{\mathrm{a}}$ colocação da RMRJ e do Estado.

Para o ano de 1990, documento de nomenclatura idêntica, isto é, "Número de estabelecimento por grandes setores e quantidade de funcionários - SG (RJ). 1990" -, cujos dados cruzados com todos os municípios do Estado revelam ganho de duas posições face as informações de 1985: o município pula da $6^{a}$ para a $4^{a}$ colocação geral e, no conjunto da 
RMRJ, igualmente avança em duas posições, de $5^{\circ}$ para $3^{\circ}$, atrás apenas da capital e de Duque de Caxias. No agrupamento destas informações paro os anos de 1985 e 1990 prepondera maior volume de unidades industriais entre 4 a 50 funcionários embora tenhamos casos entre 500 e 1000 empregados.

Neste sentido e ainda operando com dados do Ministério do Trabalho para os mesmos anos de 1985 e 1990 sobre: "Número de estabelecimento por subsetores e por números de funcionários"; "Quantidade de trabalhadores por setores" e "Quantidade de estabelecimento por três setores específicos": Conclui-se que: a) o número de estabelecimento caracterizado por "indústria têxtil" mais que triplicou entre 1985 e 1990; b) preponderância de pequenas e médias unidades industriais; c) os três setores com maior demanda de mão-de-obra são - indústria química, têxtil e de alimentos. Ora, estes são exatamente os ramos que se destacam na produção industrial local após a segunda metade do século XX. Logo:

Tabela 4: Quantidade de estabelecimento por três setores específicos:

\begin{tabular}{|l|l|l|l|}
\hline Ano & Setor Químico & Setor Têxtil & Setor de Alimentos \\
\hline 1985 & 37 & 85 & 56 \\
\hline 1990 & 62 & 270 & 67 \\
\hline
\end{tabular}

Fonte :Cruzamento feito pelo autor deste artigo de acordo com a Rais/Caged

MTE. 1985 e 1990

O setor químico apesar de quantitativo inferior aos outros dois casos em tela, demandava maior número de mão-de-obra o que pode revelar a complexidade daquela atividade. Inserido neste setor estão os tradicionais laboratórios farmacêuticos B. Braun e Ranbaxi, instalados no trecho Tribobó-Arsenal ${ }^{5}$.

Como exercício "final", convém apontar o Índice de Participação do Município (IPM) de 1990. Na ocasião o IPM da RMRJ era responsável por $74.20 \%$ no conjunto fluminense, sendo SG responsável por 1,9\%. Este percentual correspondia a $5^{\text {a }}$ colocação da RMRJ, atrás da Capital (60,3\%), Duque de Caxias (3,8\%), Niterói $(2,5 \%)$ e de Nova Iguaçu $(2,2 \%)$ e a $7^{\mathrm{a}}$ do Estado. Fora da RMRJ, São Gonçalo era superado por Volta Redonda (7,3\%) e Petrópolis (2,0\%). Por fim, há uma observação interessante a fazer e que pode ser atrelada a questão do IPM: embora não apresentasse números, o jornal $O$ Fluminense em dada edição de 1990 atribuía a São Gonçalo a $7^{a}$ economia do Estado cuja atividade industrial passou a absorver $50 \%$ da mão-de-obra ativa local. Eis um ponto aberto às novas pesquisas.

40 Explicam-se as dificuldades da indústria local na conjuntura fluminense e nacional. Por exemplo, o Estado enfrentou problemas de crescimento econômico no período, no entanto, a historiografia fluminense não partiu da premissa de que a região perdera sua identidade industrial.

41 Convém aqui voltar a mencionar o texto de Freire e Freire (2006:349) sob o título Consolidação de São Gonçalo (RJ) na periferia metropolitana e produção industrial: novas questões para a reflexão. Importante sublinhar dois aspectos que aparecem neste trabalho de forma a ressaltar o dinamismo econômico do município, conforme dados para 
o período 1996/2001: a) 5 PIB do Estado - a sua frente estão a Capital, Duque de Caxias, Niterói e Volta Redonda (apud fundação CIDE); b) 1069 estabelecimentos em 2001 - sendo os setores que mais empregam: confecção, alimentos e químico-farmacêutico. Repousa assim um exemplo da transformação pela qual passou a indústria gonçalense. $O$ tom tão anunciado da crise parece não encontrar eco enquanto ocorrência da desindustrialização irrefreável. Em suma, tentamos mostrar as dissonâncias deste discurso.

\section{Novos estudos: antigas perspectivas analíticas}

Na pesquisa de mestrado conceituamos de corrente da crise o discurso ao qual nos referimos acima. Tais trabalhos conferem muita importância a decadência total da indústria gonçalense. Passados 8 anos de "concluída" a dissertação de mestrado identificamos reflexões não necessariamente produzidas por historiadores: apresentam em seu conjunto autores no campo do (a) geografia, engenharia ambiental, direito, biologia e economia. Contudo, também reverberam a ideia de crise no setor produtivo local no período em análise.

Como exemplo, nos prende a atenção o trabalho de autoria coletiva - "A integração de políticas públicas na ação contra enchentes em bacias hidrográficas antropizadas: o caso do município de São Gonçalo/RJ" (s/d). 0 tema da atividade industrial gonçalense aparece na lateralidade deste estudo. A caracterização principal é a de que com a crise da cultura agrícola eclode no município o fenômeno da indústria nas décadas de 1940 e 1950. Ora, já dissemos aqui e igualmente demonstramos em estudos anteriores que o advento da indústria gonçalense marca do início do século XX. Ainda segundo o estudo acima, a cidade logo perde seu "padrão econômico" com o fechamento de algumas fábricas e a transferência de unidades para outras regiões do Estado, embora tais não sejam identificadas. Por fim, assevera que, hoje, a principal fonte de arrecadação do município se pauta no Imposto Predial e Territorial Urbano e de repasses estaduais. Esta interpretação é no mínimo questionável e urge por maiores problematizações. Defende ainda que a perda de unidades fabris levou a população local a procurar postos de trabalhos em cidades vizinhas. Mas veja, considerando a existência de uma espécie de época de ouro da indústria local, esta nunca fora a principal empregadora do município. Como afirmamos em linhas acima.

Quase nestas mesmas perspectivas anteriores e de um completo esvaziamento industrial da cidade, seguem alguns trabalhos. Estamos nos referindo aos seguintes textos: Apogeu e crise de um espaço industrial: o caso do leste da Baia de Guanabara (COSTA et al, s/d); Contradição espacial na região metropolitana do Rio de Janeiro / Brasil: o rural e o urbano no município de São Gonçalo (SILVEIRA et al, s/d); Espaço do trabalho e mudanças socioepacias: a reconstrução dos espaços urbanos-fabris no município de São Gonçalo, Estado do Rio de Janeiro (MORAES, 2014) e, - O processo de esvaziamento industrial em São Gonçalo no século XX: auge e declínio da "Manchester Fluminense" (ARAÚJO e MELO, 2014).

O (a) leitor (a) já identificou que nossa interpretação acerca destes problemas apresenta nuances diferentes. Embora do fechamento de importantes plantas na tradicional área de concentração industrial, no caso, o Distrito de Neves - houve uma espécie de espraiamento de pequenas e médias unidades industriais por todos os demais distritos da municipalidade em tela. 
Esta nossa interpretação encontra ressonância em texto publicado, ao que parece, na década de 1980. Trata-se do seguinte trabalho - Localização e relocalização industrial: Região Metropolitana do Rio de Janeiro /setor oriental (TEIXEIRA, s/d). Após análise dos seguintes documentos: Cadastro Industrial - IBGE - 1965; Cadastro Industrial - IDEG - 1976 e pesquisa de campo realizada em 1981 - a autora analisa e conclui acerca de novos alinhamentos, ou seja, o processo de relocalização da indústria pela cidade em estudo. Um destes alinhamentos secundários, isto é, fora do eixo do Distrito de Neves, se verifica no eixo Tribobó (bairro gonçalense) Maricá (município vizinho). Cortado pela RJ 106, para ilustrar, nesta região está o bairro do Arsenal com 3 instalações do setor médicohospitalar-farmacêutico cuja alusão fizemos anteriormente: B.Braun, Ranbaxi do Brasil e Hartmam. Segue a conclusão alcançada pela autora que aqui queremos enfatizar:

“(...). Um caráter específico apresenta o eixo ao longo da RJ-106 que se dirige para Maricá. Esse eixo apresenta unidades de minerais não metálicos como os demais, mas apresenta também unidades ligadas a produtos farmacêuticos, alimentares, plástico, mecânica e mobiliário, totalizando 21 estabelecimentos, predominantemente médios" (TEIXEIRA, s/d, pp 19-24).

É este olhar que oferecemos como principal contribuição para pensar o evento da indústria em SG. E, como pistas, para encaminhamento da conclusão, oferecemos igualmente outros pontos que aguardam investigação. São eles:

A relação entre crescimento da população municipal e a capacidade da economia local na absorção da mão-de-obra disponível; o fenômeno do crescimento urbano acelerado face ao "barateamento" do preço da terra em comparação com cidades como Niterói e Rio de Janeiro; o advento do capital imobiliário fortemente em expansão no município; o grau de atuação do poder público em suas diferentes esferas e a ação da burguesia empresarial principalmente a partir da Associação Comercial e Industrial de São Gonçalo (ACISG), sem esquecer, é verdade, do Centro Industrial do Rio de Janeiro (CIRJ) e depois da Federação das Indústrias do Estado do Rio de Janeiro (FIRJAN) e a circunvizinhança entre os bairros de Neves (SG) e Barreto (Niterói), ambos possuíam identidade industrial.

Outra gama estudos repousa sobre um tema geral, qual seja: a história das empresas e dos empresários que atuaram na cidade. Dito de outra forma, é preciso estudar a história do capitalismo em SG. Sendo assim, é hora de indicarmos alguns casos que merecem atenção analítica, tanto de empresas, ferrovias e portos aludidos ao longo do artigo quanto de empresários como: Carlos Guianeli, Henrique Lage e Francis Hime.

Por fim, a questão operária também não foi nosso objeto de análise neste turno, porém merece igual atenção dos pesquisadores. Rica e fundamental reflexão sobre este tema repousa no trabalho de Fernandes (2009), este se debruçou no que caracterizou de SG operário. 0 estudioso pesquisou a organização, a luta de parcela da classe operária local e o papel da bancada comunista na câmara municipal. $O$ autor analisa o que categoriza como espaços dinâmicos de formação da classe operária gonçalense constituído nos (as) ou pelos (as): fábricas, bairros, praças públicas, entidades sindicais operárias e no parlamento municipal.

\section{Considerações finais}

51 Toda paisagem revelada permite multiplicidade de olhares. Diferentes matizes e vernizes pairam sobre um enquadramento. A compreensão que estabelecemos da indústria gonçalense e sua relação com o contexto fluminense posterior a 1960 ao tempo que 
inaugura um quadro analítico o oferece às interpretações e às expectativas de outros estudos. Ao longo deste artigo deixamos pistas de outras paisagens a serem esquadrinhadas. Procuramos debater a relevância do setor industrial que se manteve bastante variado. Indicamos onde reside a diversificação, isto é, os principais setores que compõem a paisagem industrial da cidade. Em síntese, trabalhamos com as ideias de mudança no perfil produtivo industrial; reestruturação; transformação; mudança no perfil espacial da indústria para além do distrito de Neves; os novos espaços ocupados; relocalização e (re)espacialização. Nosso olhar buscou contrapor à memória do esvaziamento e da perda definitiva da capacidade industrial gonçalense no período de que se debruça esta análise.

O fechamento de grandes unidades provocou "sentimento" de esvaziamento definitivo do setor. Não obstante, a SG continuava a ser apresentada como a cidade da indústria pelos periódicos locais. 0 município posicionava-se entre os mais importantes da configuração fluminense no que tange a movimentação e participação industrial, embora o próprio Estado e o país tenham passados por vicissitudes econômicas principalmente nas décadas de 1970 e 1980. Há certa negligência quando se reporta ao passado industrial da cidade, cujo evento contribuiu para a identidade e centralidade daquele município guanabarino. Vemos na atividade industrial gonçalense a possibilidade de redefinir o papel histórico do município no contexto fluminense. Na verdade, negligenciar a atividade industrial local é parte integrante de uma visão periférica da cidade, ainda muito predominante. Oferecemos leituras diferentes. Em suma, esperamos ter demonstrado a riqueza da indústria local. Que a interpretação aqui percorrida possa de algum modo contribuir na construção de uma massa crítica.

Em termos de produção historiográfica da indústria fluminense acreditamos que a pesquisa inaugura a construção de um pensamento crítico acerca da indústria em SG posterior a 1960. Muitos aspectos aguardam respostas e, portanto, oferecidos à crítica e ao debate. De alguma forma foi nossa ideia contribuir para a historiografia regional e para as sociedades gonçalense e fluminense. Subsequente aos anos 1960 SG possui uma capacidade produtiva instalada que curiosamente não é lembrada. A questão é vista com pouca ênfase. Uma paisagem acinzentada.

\section{BIBLIOGRAFIA}

ANDRADE, T.A.G.; RIBEIRO, J.C.F.; SILVA, E.R., e MATTOS, U.A.O. A integração de políticas públicas na ação contra enchentes em bacias hidrográficas antropizadas: o caso do município de São Gonçalo (RJ). [s/d.] < http://www.eng.uerj.br/publico/anexos/1281057384/ Aintegracaodepoliticaspublicas.pdf >. Acessado em 29 de dezembro de 2017.

ARAÚJO, Victor Leonardo de. MELO, Hildete Pereira de. 0 processo de esvaziamento industrial em São Gonçalo no século XX: auge e declínio da "Manchester Fluminense". Cadernos do desenvolvimento fluminense. n, 4, mai. pp. 65-87.[2014]. <http://www.e-publicacoes.uerj.br/ index.php/cdf/article/view/11532/9081>. Acessado em 31 de dezembro de 2017. 
BEAUCLAIR, Geraldo; Honorato, Cezar. Niterói industrial: ramos da pré-indústria. In: Temas de histórias de Niterói - Cidade Múltipla, Niterói, RJ: Niterói Livros, 1997.

BRAGA, Maria Carvalho. O Município de São Gonçalo e sua história. São Gonçalo: Edição Independente. 2006.

COSTA, Cláudio Barbosa da; ZEFERINO, Luciano de Andrade. Apogeu e crise de um espaço industrial: o caso do leste da Baia de Guanabara. [s/d.] <http:// www.observatoriogeograficoamericalatina.org.mx/egal8/Geografiasocioeconomica/ Geografiaespacial/13.pdf >. Acessado em 5 de janeiro de 2018.

GEIGER, Pedro Pinchas e OUTROS. Urbanização e industrialização na orla oriental da Baía de Guanabara. Revista Brasileira de Geografia - RBG. Rio de Janeiro: IBGE, out/dez.,1956.

FERNANDES, Marcelo Belarmino. São Gonçalo operário: cenários e personagens das lutas sociais no município de São Gonçalo no segundo pós-guerra, 1945-1951. São Gonçalo. Dissertação de Mestrado em História. Programa de Pós Graduação em História Social, Universidade do Estado do Rio de Janeiro, Faculdade de Formação de Professores, 123p., 2009.

FREIRE, Désirée Guichard \& FREIRE, Denise Guichard. Consolidação de São Gonçalo (RJ) na periferia metropolitana e produção industrial: novas questões para a reflexão. In. SILVA, C. A.; FREIRE. D. G.; OLIVEIRA. F.J.G. (orgs.). Metrópole: governo, sociedade e território. Rio de Janeiro: DP\&A: Faperj, 2006.

LIMONAD, Ester. Os lugares da urbanização - o caso do interior fluminense. São Paulo, Tese de doutorado em Arquitetura. Programa de Pós Graduação em Estruturas Ambientais Urbanas, Universidade de São Paulo, 247p., 1996.

MENDONÇA. Adalton da Motta. Breve história da indústria gonçalense. MEMOR. 1996. Caixa n.ำ 2.

MORAES, João Marçal Bodê de. Espaço do trabalho e mudanças socioepacias: a reconstrução dos espaços urbanos-fabris no município de São Gonçalo, Estado do Rio de Janeiro. Meridiano Revista de Geografia, Buenos Aires: Centro de Estudios Alexander von Humboldt, n. 3, p. 67-82, [2014]. <http://www.revistameridiano.org/n3/05/>. Acessado em 10 de janeiro de 2018.

OLIVEIRA. Floriano José Godinho de. Reestruturação produtiva e regionalização da economia no território fluminense. São Paulo, Tese de Doutorado em Geografia, Programa de Pósgraduação em Geografia Humana, Universidade de São Paulo, 218p., 2003.

SILVEIRA, D.M; SIMÕES, G.S; SILVA, C.C. dos S e SILVEIRA, R.M. Contradição espacial na região metropolitana do Rio de Janeiro / Brasil: o rural e o urbano no município de São Gonçalo. [s/ d.]. <http://observatoriogeograficoamericalatina.org.mx/egal12/Geografiasocioeconomica/ Geografiaurbana/175.pdf>. Acessado em 22 de janeiro de 2018.

TEIXEIRA, Marlene P.V. Localização e relocalização industrial: Região Metropolitana do Rio de Janeiro (setor oriental). [s/d.]. < https://revistas.ufrj.br/index.php/aigeo/article/ view/5855/4452>. Acessado em 28 de janeiro de 2018.

\section{Documentação}

A Cerj e a história da energia elétrica no Rio de Janeiro. Rio de Janeiro. Centro de Memória da Eletricidade no Brasil - CERJ. 1993.

AZEVEDO, José Afonso Mendonça. Consolidação de Legislação do Município de São Gonçalo. Organizada por determinação do Exmo. Sr. Prefeito Municipal Dr. Eugenio. Borges. Rio de Janeiro: Oficinas Gráficas do “Jornal do Brasil”, 1939. 
Cadastro Industrial do Estado do Rio de Janeiro de 1979. Federação das Indústrias do Estado do Rio de Janeiro e Centro Industrial do Rio de Janeiro.

Centro Industrial do Rio de Janeiro. Federação das Indústrias do Estado da Guanabara. A Fusão dos Estados da Guanabara e do Rio de Janeiro. Efeitos da Unificação da Guanabara - Estado do Rio de Janeiro sobre alguns complexos industriais. Vol. II. Astel Assessores Técnicos Ltda. 1969.

Federação das Indústrias do Estado do Rio de Janeiro e Centro Industrial do Rio de Janeiro. Cadastro Industrial do Estado do Rio de Janeiro. 1979.

Fundação para o Desenvolvimento da Região Metropolitana do Rio de Janeiro. Organização Espacial Metropolitana. Política de Localização Industrial. DIPLAN / FUDREM. 1976.

Guia socioeconômico dos municípios do Estado do Rio de Janeiro. SYDENSTRICKER, Iara (Coord.). Vol. 1. Região Metropolitana. Rio de Janeiro: Graf. JB, 1993.

IBGE. Censos demográficos e econômicos. 1940. Série Regional. Parte 15. Rio de Janeiro. . Censo Industrial do Estado do Rio de Janeiro. Ano de 1950.

Recenseamento de 1920. Vol. IV. $5^{\text {a }}$ parte. Tomo I. População. CDDI e Recenseamento demográfico de 1920. Estado do Rio de Janeiro: Municípios.

. Recenseamento Geral. Ano de 1960.

. Recenseamento Geral de 1950. População presente, por sexo e situação do domicílio, segundo as zonas fisiográficas, os municípios e os distritos.

. São Gonçalo, Rio de Janeiro: Coleção de Monografias. n. 479. $2^{\mathrm{a}}$ ed., 1970.

Instituto de Estudos Políticos e Sociais. Projeto Pró-Rio. Problemas e Potencialidades do Estado do Rio de Janeiro. Situação Econômica. Relatório Geral 2º Vol. Seção IV. Rio de Janeiro 1983.

Jornal O Fluminense: 21 e 22 Set. 1980. Suplemento Especial de São Gonçalo. Ano 90; Set. 1990. Ano CXIII. n. 26.741.

Jornal O São Gonçalo: 12 set. 1950. n. 1.036. Ano XX; 12 nov. 1965. n. 4.245. Ano XXXV; 17 de mar. 1970. Ano LX. n. 5.235.

Ministério do Trabalho e Emprego. Relação Anual de Informações Sociais e Cadastro Geral de Empregados e Desempregados. 1985.

. Relação Anual de Informações Sociais e Cadastro Geral de Empregados e Desempregados. 1990.

PALMIER. Luiz. São Gonçalo Cinquentenário. Rio de Janeiro: IBGE, 1940.

PEÇANHA, Celso (Governo). Monografias de Municípios Fluminenses. Elaboradas pela Flumitur e Coterj. Governo Celso Peçanha. 1962. vol. 1

\section{NOTAS}

1. Trecho do hino oficial de São Gonçalo. A expressão entre aspas do título deste artigo dá forma ao poema de Geraldo Pereira Lemos, letrista do hino da cidade, professor, poeta, escritor e jornalista gonçalense.

2. Município da Região Metropolitana do Estado do Rio de Janeiro situado no entorno guanabarino, cortado pela BR 101 e pelas rodovias estaduais: RJ 104 e RJ 106. 
3. Este artigo é reflexo da dissertação de mestrado intitulada - A paisagem revelada: natureza da concentração industrial em São Gonçalo (RJ) - crise ou reestruturação da indústria local? Apresentada em 2010 ao Programa de Pós-Graduação em História Social, da Faculdade de Formação de Professores da Universidade do Estado do Rio de Janeiro. Orientação do Prof. Dr. Sydenham Lourenço Neto.

4. Área que após a fusão do antigo ERJ com o Estado da Guanabara deu origem a Região Metropolitana do Estado do Rio de Janeiro, nucleada pela cidade do Rio de Janeiro.

5. São bairros que estão no entroncamento das RJ's 104 e 106.

\section{RESUMOS}

$\mathrm{O}$ passado industrial gonçalense tem sido insistentemente interpretado sob a premissa que evidencia o fenômeno da desindustrialização total. O olhar tem sido fragmentado, especialmente para o período que compreende a segunda metade do século XX. Nossa preocupação reside em discutir o quadro da atividade industrial local até 1990 e sua articulação com o contexto fluminense. Parece-nos mais evidente a ocorrência da reestruturação industrial gonçalense na medida em que sublinharemos os novos setores da atividade produtiva bem como os novos espaços ocupados.

The industrial past of gonçalense has been insistently interpreted under the premise that shows the phenomenon of total deindustrialization. The look has been fragmented, especially for the period comprising the second half of the twentieth century. Our concern is to discuss the framework of local industrial activity until 1990 and its articulation with the fluminense context. It seems more evident to us the occurrence of the industrial restructuring of gonçalense to the extent that we will emphasize the new sectors of the productive activity as well as the new spaces occupied.

El pasado industrial gonçalense ha sido insistentemente interpretado bajo la premisa que evidencia el fenómeno de la desindustrialización total. La mirada ha sido fragmentada, especialmente para el período que comprende la segunda mitad del siglo XX. Nuestra preocupación reside en discutir el cuadro de la actividad industrial local hasta 1990 y su articulación con el contexto fluminense. Nos parece más evidente la ocurrencia de la reestructuración industrial gonçalense en la medida en que subrayar los nuevos sectores de la actividad productiva así como los nuevos espacios ocupados.

Le passé industriel de São Gonçalo a été interprété avec insistance sous la prémisse qui met em évidence le phénomène de désindustrialisation totale. Le regard a été fragmenté, en particulier pour la période qui comprend la seconde moitié du XXe siècle. Notre préoccupation est de discuter le cadre de l'activité industrielle locale jusqu'à 1990 et son articulation avec le contexte de Rio. Il nous semble plus évident l'occurrence de la restructuration industrielle de São Gonçalo dans la mesure où nous mettrons l'accent sur les nouveaux secteurs de l'activité productive, ainsi que sur les nouveaux espaces occupés. 
ÍNDICE

Mots-clés: industrie; crise industrielle; restructuration.

Palabras claves: la industria; crisis industriales; reestructuración.

Palavras-chave: indústria; crise industrial; reestruturação.

Keywords: industry; industrial crisis; restructuring.

\section{AUTOR}

\section{JOSÉ LUÍS HONORATO LESSA}

Doutorando do Programa de Pós Graduação em História, Política e Bens Culturais do Centro de Pesquisa e Documentação de História Contemporânea do Brasil da Fundação Getúlio Vargas.

Professor da Universidade Salgado de Oliveira e da Secretaria de Estado de Educação (RJ). E-mail: honorato.lessa@gmail.com 